Independent Journal of Management \& Production (IJM\&P) ISSN: 2236-269X DOI: 10.14807/jmp.v3i1.22

v. 3, n. 1, January - June 2012

\title{
THE INFLUENCE OF A MATHEMATICAL MODEL IN PRODUCTION STRATEGY: CONCEPTUAL DEVELOPMENT AND EMPIRICAL TEST
}

\author{
Dn. Paulo César Chagas Rodrigues \\ Instituto Federal de Educação, Ciência e Tecnologia de São Paulo - Brazil \\ E-mail: paulo.rodrigues@ifsp.edu.br \\ Dr. Fernando Augusto Silva Marins \\ Universidade Estadual Paulista (FEG/UNESP) - Brazil \\ E-mail: fmarins@feg.unesp.br \\ Dr. Fernando Bernardi de Souza \\ Universidade Estadual Paulista (FEB/UNESP) - Brazil \\ E-mail: fbernardi@feb.unesp.br \\ Submission: $15 / 04 / 2012$ \\ Accept: 20/05/2012
}

\begin{abstract}
Acquire and produce what is strictly necessary are the goals of the organizations, since they aim companies more competitive and thereby reducing production costs. The research method is applied in nature, with a qualitative and quantitative approach, in which the objective of the research will be: exploratory and descriptive, with technical procedures, divided into: bibliographic, documentary, survey and concluding with a case study. On this assumption the main objective of this research is to develop and analyze a mathematical model that minimizes costs and maximizes the postponement of stocks in a company in the pulp, paper and paper products. Having been found only four papers, two articles and two theses that deal with the issue of demand management, supply chain and inventory postponement. These studies address the issue by modeling the productive time of the supply chain. For production segments this research may enable development of management practices demand and production strategy, allowing cost reductions and productivity gains possible. With the development of the mathematical model could ever analyze the behavior of demand and its influence on the productive strategy, strategy formulation regarding the purchase of raw materials and finished product storage in the last four years the company's results for the proposed model.
\end{abstract}


Independent Journal of Management \& Production (IJM\&P) ISSN: 2236-269X DOI: 10.14807/ijmp.v3i1.22

v. 3, n. 1, January - June 2012

Keywords: Production strategy, demand management, mathematical modeling, S\&OP.

\section{INTRODUCTION}

From the event RIO +20 in 2012 , organizations need to spend worrying not only to reduce production costs, but to be optimizing the consumption of raw materials in order to acquire what is strictly necessary to its production.

The Brazilian business environment has undergone significant changes in recent decades, these changes increase the competitive level of demand from customers, global economic and political moments and the dynamic marketing increasingly unstable, creating increasing challenges for companies in understanding demands.

From this context, management models and operations were suffering adjustments, considered pioneers by companies as a way to adapt to the new political and economic world, becoming a focus of academic study and application by other companies.

Assuming that companies need to be more competitive when compared to competitor and market consumer, they are always looking for new ways to reduce production costs and increase their competitiveness. The study of strategies for production and mathematical modeling as a way to develop a model that allows to reduce production costs and the storage of raw materials, process and in the finished product.

Modeling is a method of quantitative research of an applied nature, refers to research on models of causal relationships between control variables and performance variables which can be developed, analyzed or tested (BERTRAND; FRANSOO, 2002).

Lawrence and Pasternack (2001) discuss the mathematical programming is the branch of science that deals with the management of optimization problems, in which we want to maximize a function (such as the return of profit, expected, or 
Independent Journal of Management \& Production (IJM\&P) ISSN: 2236-269X DOI: 10.14807/ijmp.v3i1.22

v. 3, n. 1, January - June 2012

efficiency) or minimize a function (such as cost, time or distance), usually in a restricted environment.

According to Goldberg (2000), the need to represent the context of reality simply brought forth the concept of modeling, which is defined as a process of finding a well-structured vision of reality, models are simplified representations of reality, to certain situations and approaches.

Starting from these premises the aim of this research is to develop a mathematical model that will maximize the deferral of inventory, minimizing costs, for both this modeling is based on the study of manufacturing strategies and mathematical modeling.

Ko, Mehnen and Tiwari (2010) add that a mathematical structure allows us to treat and represent uncertainties in the self-perception of uncertainty, imprecision, partial truth, and lack of information.

Allen and Schuster (2004) add that mathematical programming is often the tool used for modeling strategies in conditions of uncertainty. These models are static in nature, assuming that the probabilities of occurrence are known beforehand and that all decisions are taken at the same time.

\section{DYNAMIC STOCHASTIC PROGRAMMING MODEL}

According to García-Dastugue (2003), the demand process, the fundamental equations of the model of safety stock, and the optimization problem, are described below.

Graves and Willems (2000) and García-Dastugue (2003) discuss that process in external demand is observed stages of demand that is based on a stationary process with a daily average $(\mu)$. Demand for internship, are all steps that are not considered stages of demand are the sum of the demand of each customer multiplied by the value of the corresponding arc.

According to García-Dastugue (2003), a way to produce the upper limit of demand is assumed that demand is normally distributed and uses the average demand, standard deviation of demand and factor of safety to produce the upper limit according to Equation 1. 
Independent Journal of Management \& Production (IJM\&P) ISSN: 2236-269X

$$
D_{j}(\tau)=\tau \mu_{j}+k \sigma \sqrt{\tau}
$$

Onde:

$D_{j}(\tau)$ Upper limit of demand over days of exposure in stage $\mathrm{j}$

$\tau \quad$ Days of Exposure

$k \quad$ Safety factor

$\sigma \quad$ Standard deviation of demand

Graves and Willems (2000) and Garcia-Dastugue (2003) comment that the number of days of exposure ( $t$ ) depends on time of processing stages, the input service time is the maximum time it takes replenishment from all providers and service time quoted is the time promised to the customer the next layer, as stated in Equation 2.

$$
\tau=S I_{j}+T_{j}+S_{j}
$$

Onde:

$\tau \quad$ Days of Exposure

$S I_{j} \quad$ Weather service entry

$T_{j} \quad$ Stage processing time

$S_{j} \quad$ Service time quoted to the next level of customer

The inventory model of security can be defined as the expected inventory level on a stage at the end of each period is the safety stock planned for the stage. At the end of each period, it is expected that the stock throughout the cycle has been used. Equations 3:04 from the expected inventory level at the end of stage time $t \mathrm{j}$ (GRAVES; WILLEMS, 2000; GARCÍA-DASTUGUE, 2003).

$$
\begin{aligned}
E\left[I_{j}\right]=D_{j}\left(S I_{j}\right. & \left.+T_{j}+S_{j}\right)-\left(S I_{j}+T_{j}+S_{j}\right) \mu_{j} \\
& =D_{j}(\tau)-\mu_{j} \tau
\end{aligned}
$$

The authors complement discoursing expected that the inventory at the end of period $t$ of stage $j$ is equal to the upper limit of the average demand least during the exposure time. 
Independent Journal of Management \& Production (IJM\&P) ISSN: 2236-269X

According Garcia-Dastugue (2003), the optimization problem is designed to find optimal inventory levels, i.e. the level of said stock to customers the next level, as described in Equations 5, 6, 7, 8 and 9.

$$
\begin{gathered}
P=\min \sum_{j=1}^{N} h_{j}\left[D_{j}\left(S I_{j}+T_{j}-S_{j}\right)-\left(S I_{j}+T_{j}-S_{j}\right) \mu_{j}\right] \\
S_{j}-S I_{j} \leq T_{j} \text { for } j=1,2, \ldots N \\
S_{j}-S I_{i} \geq 0(\text { for all }(i, j) \in A \\
S_{i} \leq S_{i} \text { for all demand nodes } j \\
S_{j}, S I_{j} \geq 0 \text { and integer for } j=1,2, \ldots N
\end{gathered}
$$

Onde:

P Postponement

$D_{j}(\tau)$ Upper limit demand over time exposure

$h_{j} \quad$ Rate of annual insurance cost

$S I_{j} \quad$ Time service entry

$T_{j} \quad$ Processing Stage Time

$S_{j} \quad$ Quota-time service to the next level of customer

$\mu_{j} \quad$ Average demand expected

$S_{i} \quad$ Share of maximum service to customer's next level

Rogers, Ribeiro and Rogers (2004) report that in some environments, especially in manufacturing, the application does not come all at once as the EOQ assumes, but in fractions, and this premise, sets up what should be the minimum volume being produced, at which production costs does not exceed the total cost.

According to Garcia-Dastugue (2003), the optimization problem is to minimize the sum of the cost multiplied by the inventory level at all stages of the supply chain.

\subsection{Definitions}


Independent Journal of Management \& Production (IJM\&P) ISSN: 2236-269X

In this model, the objective function is to minimize the cost and maximize the delay inventories of raw, in-process and final product. The constants that will permit the implementation of the objective function are: Demand $(D j)$, the proportion of each product being made on a monthly basis, the volume of paper used in each of the products in grams $(\mathrm{Y} 1)$, ink volume in milliliters $(\mathrm{Y} 2)$, volume of wire in meters $(\mathrm{Y} 3)$, envelope in units (Y4), foil stickers on units (Y5), Cover and cover units (Y6), processing time in minutes ( $\mathrm{Y} 7)$ and cost $(\mathrm{Y} 8)$.

\subsection{Decision variables}

The decision variables used in this model are: number of books of 400 sheets (X1) and 200 sheets (X2), because these two variables will display the quantity to be produced of each product each month and will together with the constants Y1, Y2, $\mathrm{Y} 3, \mathrm{Y} 4, \mathrm{Y} 5, \mathrm{Y} 6, \mathrm{Y} 7$ and $\mathrm{Y} 8$ allow minimize the production costs, while maximizing the delay inventories.

The variables $\mathrm{X} 1$ and $\mathrm{X} 2$ will be influenced by the estimated demand as per the information of the last quadrennium, which will influence the decision about what to buy and in what quantity.

From this influence can be observed the behavior of manufacturing strategy as the strategy of purchasing, production and storage by the proposed model.

\subsection{Constraints}

Equation 10 is the restriction on the sum of the quantity to produce times the volume of paper lined product during each of the periods $j=j+1$ which is the total consumption of paper in time, measures should be in weight units and (kilograms) which should be less than or equal to the sum of the respective periods, which will inform the total quantity of paper to be purchased.

$$
\sum_{j=1}^{N} P 1_{j} * Q T 1_{j}+P 2_{j} * Q T 2_{j} \leq P C_{j}(\text { for } j=1,2, \ldots 12)
$$

The restriction referenced in Equation 11 is the sum of the quantities produced during periods $j=j+1$ which will unit of measurement units, which should be less than or equal to the sum of the units to produce the respective periods. 


$$
\sum_{j=1}^{N} Q T 1_{j}+Q T 2_{j} \leq U P_{j}(\text { for } j=1,2, \ldots 12)
$$

Equation 12 wherein the restriction reference is made sum of the periods $\mathrm{j}=\mathrm{j}$ +1 , products $X 1$ and $X 2$, which is calculated on the amount of product produced times the total amount of ink used in liters in each of periods which should be less than or equal to the sum of the periods in which 12 were purchased inks.

$$
\sum_{j=1}^{N} T 1_{j} * Q T 1_{j}+T 2_{j} * Q T 2_{j} \leq T C_{j}(\text { for } j=1,2, \ldots 12)
$$

The constraint of Equation 13 is calculated the sum of the periods $j=j+1$, products $\mathrm{X} 1$ and $\mathrm{X} 2$, which is calculated on the amount of product produced times the total amount of wire used for each of the periods which must be less or equal to the sum of the periods in which 12 were purchased inks.

$$
\sum_{j=1}^{N} A 1_{j} * Q T 1_{j}+A 2_{j} * Q T 2_{j} \leq A C_{j}(\text { for } j=1,2, \ldots 12)
$$

In Equation 14 is treated restriction which is the sum of the capacity in each period $\mathrm{j}=\mathrm{j}+1$, which should be less than or equal to the sum of the demands of each of the 12 periods.

$$
\sum_{j=1}^{N} C P_{j} \leq D_{j}(\text { for } j=1,2, \ldots 12)
$$

Equation 15 discusses the restriction which is the sum of the units produced in each period $\mathrm{j}=\mathrm{j}+1$, which should be less than or equal to the sum of productive capacity in each of 12 periods.

$$
\sum_{j=1}^{N} U P_{j} \leq C P_{j}(\text { for } j=1,2, \ldots 12)
$$

The restriction referenced in Equation 16 states that the sum of the quantities of product produced $X 1$ must be greater or equal to 0 in each period $j=j+1$. This restriction is designed to force that exists in producing the product $\mathrm{X} 1$ and it is not negative. 
Independent Journal of Management \& Production (IJM\&P) ISSN: 2236-269X

$$
\sum_{j=1}^{N} X 1_{j} \geq 0(\text { for } j=1,2, \ldots 12)
$$

The restriction referenced in Equation 17 states that the sum of the quantities of product produced $X 2$ should be greater than or equal to 0 in each period $\mathrm{j}=\mathrm{j}+1$. This restriction is designed to force that exists in producing the product $\mathrm{X} 2$ and it is not negative.

$$
\sum_{j=1}^{N} X 2_{j} \geq 0(\text { for } j=1,2, \ldots 12)
$$

The restriction treated in Equation 18 is the sum of units of the product produced X1 must be greater than or equal to units of each product to be produced, or is the division of the units to produce the period from the sum of the proportion of each product and result multiplied by the proportion of the units to produce X1.

$$
\sum_{j=1}^{N} X 1_{j} \geq U P_{j}(\text { for } j=1,2, \ldots 12)
$$

In Equation 19 discusses the restriction which will be the sum of units of the product produced X2 should be greater than or equal to units of each product to be produced, or is the division of the units to produce the period from the sum of the proportion of each products and the result multiplied by the proportion of the units to produce $\mathrm{X} 2$.

$$
\sum_{j=1}^{N} X 2_{j} \geq U P_{j}(\text { for } j=1,2, \ldots 12)
$$

In Equation 20 states that the restriction is the sum of the products produced units $\mathrm{X} 1$ and $\mathrm{X} 2$ must be less than or equal to units produced downstream of the front and back in each period $\mathrm{j}=\mathrm{j}+1$.

$$
\sum_{j=1}^{N} U P_{j} \leq U P_{i}(\text { for } j \text { and } i=1,2, \ldots 12)
$$

In Equation 21 is the restriction on the sum of the costs of storage must be greater or equal to 0 in each period $\mathrm{j}=\mathrm{j}+1$. 
Independent Journal of Management \& Production (IJM\&P) ISSN: 2236-269X

$$
\sum_{j=1}^{N} C_{j} \geq 0(\text { for } j=1,2, \ldots 12)
$$

Equation 22 is about the restriction on the sum of the percentage of safety stock of products $\mathrm{X} 1$ and $\mathrm{X} 2$ to be produced in each period which must be greater than or equal to the sum of the percentage overall safety stock of each period.

$$
\sum_{i=1}^{N} E S 1_{i}+E S 2_{i} \geq E S_{j}(\text { for } j=1,2, \ldots 12)
$$

Onde:

P Postponement.

$C_{j} \quad$ Storage cost.

$C P 1_{j} \quad$ Cost of production of product 1.

$C P 2_{j} \quad$ Cost of production of product 2.

$Q T 1_{j}$ Quantity producing product 1.

$Q T 2_{j}$ Quantity producing product 2.

$E S 1_{i} \quad$ Stock Product Safety 1.

$E S 2_{i} \quad$ Stock Product Safety 2.

$P 1_{j} \quad$ Total weight of the leaves that will make the product 1.

$P 2_{j} \quad$ Total weight of the leaves that will make the product 2 .

$T 1_{j} \quad$ Total liters of paint used in product 1.

$T 2_{j} \quad$ Total liters of paint used in product 2.

$A 1_{j} \quad$ Length in meters of wire used to make the product 1.

$A 2_{j} \quad$ Length in meters of wire used to make the product 2.

$U P_{j} \quad$ Total units to be produced.

$C P_{j} \quad$ Production capacity in the period. 
Independent Journal of Management \& Production (IJM\&P) ISSN: 2236-269X DOI: 10.14807/ijmp.v3i1.22 V. 3, n. 1, January - June 2012

$D_{j} \quad$ Actual demand in period.

$A C_{j} \quad$ Quantity to buy of Wire in the period in meters.

$T C_{j} \quad$ Ink Supply to buy in the period in liters.

$P C_{j} \quad$ Quantity to buy paper in the period in Kilograms.

$X 1_{j} \quad$ Product 1.

$X 2_{j} \quad$ Product 2.

$U P_{i} \quad$ Units producing Downstream Cover.

\subsection{Objective function}

From this model we intend to get a sense of the costs of production, watching what and how much to buy and creating policies replenishment of inventories of raw materials and finished product.

It is intended to maximize the delay, minimizing the costs of production and storage of stocks of raw material and finished product and maximize the postponement of inventories of raw materials, in process and finished products, this model will be tested with more than one type, which will be exemplified in Equation 23.

$$
P=\min \sum_{j=1}^{N} C_{j}\left[C P 1_{j} * Q T 1_{j}+C P 2_{j} * Q T 2_{j}\right]
$$

\section{ILLUSTRATIVE EXAMPLE}

Table 1 shows the items to be produced, which were defined as notebook sheets 400 and 200, the Constant paper (Y1) means the amount of paper being used measurement unit used was $\mathrm{kg}$, paints (Y2) means amount of ink to be used and the unit of measure used was liters wire (Y3) means the quantity of wire to be used and the unit of measure used was meters envelope (Y4), adhesives (Y5), cover (Y6) signify amount was used of these products and the unit of measure used parts, time (Y7) means the production time of a unit of each product and unit of measure used 
Independent Journal of Management \& Production (IJM\&P) ISSN: 2236-269X DOI: 10.14807/jmp.v3i1.22

v. 3, n. 1, January - June 2012

was minute and finally cost (Y8) means that the cost of producing a unit of each product and this expressed in Real.

Table 1: Items to produce

\begin{tabular}{|c|c|c|c|c|c|c|c|c|}
\hline \multicolumn{9}{|c|}{ Produce Items } \\
\hline Product & Sheets Y1 & Paints Y2 & Wire $\mathrm{Y} 3$ & Envelope Y4 & adhesives Y5 & Cover Y6 & Time $Y 7$ & Cost Y8 \\
\hline Notebook 400 sheets $X 1$ & 0,400 & 0,700 & 1 & 1 & 1. & 2 & 20 & 0,75 \\
\hline Notebook 200 sheets $X 2$ & 0,250 & 0,350 & 0,87 & 1 & 1. & 2 & 10 & 0,50 \\
\hline
\end{tabular}

Table 2 deals with the inventory levels of product safety Notebook 400 and 200 sheets, which are expressed in percentages during the 12 months since the volumes of safety stocks may vary, depending on the volume to be produced in the month.

Table 2: Safety stock of items to be produced in\%

\begin{tabular}{|l|r|r|r|r|r|r|r|r|r|r|r|r|}
\hline \multicolumn{10}{|c|}{ Stock of the Produce Safety Items in\% } \\
\hline & January & February & March & April & May & June & July & August & September & October & November & December \\
\hline ES1 & 0,1467 & 0,1591 & 0,1577 & 0,0979 & 0,1164 & 0,1417 & 0,1408 & 0,1623 & 0,1094 & 0,1462 & 0,1426 & 0,1638 \\
\hline ES2 & 0,0309 & 0,0127 & 0,0208 & 0,0237 & 0,0303 & 0,0228 & 0,0365 & 0,0267 & 0,0269 & 0,0355 & 0,0249 & 0,0279 \\
\hline
\end{tabular}

Table 3 shows the proportion of units to be produced per month of each product notebook sheets 400 and 200 , this ratio may vary as required monthly to be produced from each template.

Table 3: Proportion of units to be produced per month

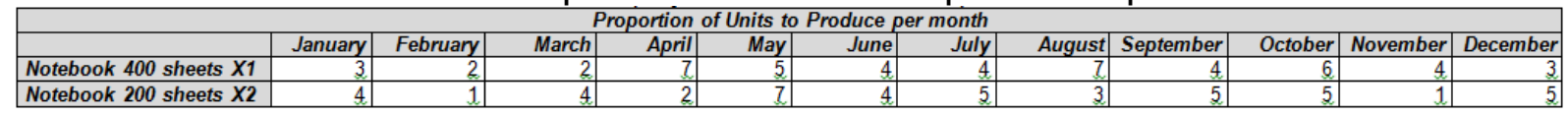

Table 4 shows the amount of products to be produced Notebook 400 and 200 sheets, in the course of 12 months, this table there are some constants that must be nurtured by the management of the company, in which we have storage cost $\left(C_{j}\right)$, demand $\left(\mathrm{d}_{\mathrm{j}}\right)$, production capacity $\left(\mathrm{CP}_{\mathrm{j}}\right)$, the units produce $\left(\mathrm{UP}_{\mathrm{j}}\right)$ and units due to the customer $\left(\mathrm{UC}_{\mathrm{j}}\right)$, and based on this information in Tables 4,5 and 6 will generate information on the expected purchases of raw materials, this volume already being planned margin of safety stock.

Table 4: Proportion of units to be produced per month

\begin{tabular}{|c|c|c|c|c|c|c|c|c|c|c|c|c|c|c|}
\hline Period & Qtd X1 & Qtd X2 & $C_{j}$ & $D_{j}$ & $C P_{i}$ & $U P_{i}$ & $U C_{i}$ & $U P_{i}$ & $P C_{i}$ & $I C_{i}$ & $A C_{i}$ & $E C_{-j}$ & $A D_{j}$ & $E S_{j}$ \\
\hline January & 365 & 485 & 0,89 & 1000 & 900 & 850 & 800 & 1700 & 267,31 & 425,40 & 787,00 & 850 & 850 & 0,0807 \\
\hline February & 925 & 475 & 0,97 & 1500 & 1450 & 1400 & 1400 & 2800 & 488,74 & 813,72 & 1338,24 & 1400 & 1400 & 0,1094 \\
\hline March & 830 & 1670 & 0,89 & 3000 & 3000 & 2500 & 2200 & 5000 & 749,52 & 1165,54 & 2282,91 & 2500 & 2500 & 0,0662 \\
\hline April & 2132 & 568 & 0,97 & 3000 & 2900 & 2700 & 2600 & 5400 & 994,75 & 1691,09 & 2626,12 & 2700 & 2700 & 0,0823 \\
\hline May & 1912 & 3038 & 0,89 & 5000 & 4958 & 4950 & 4945 & 9900 & 1524,33 & 2401,76 & 4555,08 & 4950 & 4950 & 0,0635 \\
\hline June & 3621 & 4079 & 0,97 & 8000 & 7800 & 7700 & 7600 & 15400 & 2468,12 & 3962,28 & 7169,70 & 7700 & 7700 & 0,0787 \\
\hline July & 2598 & 3852 & 0,89 & 7000 & 6500 & 6450 & 6448 & 12900 & 2002,25 & 3166,92 & 5949,28 & 6450 & 6450 & 0,0785 \\
\hline August & 2038 & 940 & 0,97 & 3000 & 2980 & 2978 & 2871 & 5956 & 1050,20 & 1755,60 & 2855,80 & 2978 & 2978 & 0,1195 \\
\hline September & 907 & 1088 & 0,89 & 2000 & 1999 & 1995 & 1896 & 3990 & 634,86 & 1015,85 & 1853,62 & 1995 & 1995 & 0,0644 \\
\hline October & 701 & 539 & 0,97 & 1250 & 1247 & 1240 & 1239 & 2480 & 415,13 & 679,30 & 1169,91 & 1240 & 1240 & 0,0981 \\
\hline November & 763 & 187 & 0,89 & 1000 & 992 & 950 & 945 & 1900 & 351,97 & 599,60 & 925,71 & 950 & 950 & 0,1194 \\
\hline December & 207 & 393 & 0,97 & 750 & 700 & 600 & 450 & 1200 & 180,98 & 282,29 & 548,85 & 600 & 600 & 0,0747 \\
\hline
\end{tabular}

\section{APPLICATION IN THE GRAPHIC INDUSTRY}


Independent Journal of Management \& Production (IJM\&P) ISSN: 2236-269X

This model was tested with two types of products and raw materials that compose them; it is not impediment to the inclusion of lines with new products in Table 1 which also will receive new columns to the raw materials that compose the new products, if necessary.

Table 2 also will be adding lines with new products because if it is necessary to define a margin for safety stock for the new product. As Table 3 is to be produced the proportion of each product per period, should also be included in the new product line.

Table 3 should receive more than one column must reference the new product, this column will be the variable that will show the quantity to be produced from the new product compared to others.

Shares in Tables 1, 2 and 3 are necessary because they serve as a parameter to define the values that will power the speakers' QTY X1, X2 QTY, QTY X3 ... ".

After these actions, should be reviewed in the objective function for the new product as well as the creation of constraints that will enable the implementation of the model and present the results in variables.

This model can be run in Excel since it included the tool that was used for the tests, the software plug-in Risk Solver Platform company Frontline Systems, which proved easy interaction, applicability and generation of reports, but there is other software that allows the execution of the model in Excel, for example, the software company Oracle Crystal Ball.

\section{FINAL THOUGHTS}

Because it is a constant concern for the company to remain competitive. Able to participate in the development of a mathematical model that reduces storage costs and production and at the same time observing the level of service demand as a way to increase profitability.

According to the Board of Industrial and manages the company's PCP when inserting the data model generated from previous years and the graphics of the results obtained, could ever observe the behavior department supplies relative to demand for the product spiraled notebook of 400 and 200 sheets.

Data were entered in a monthly model for the last four years, which allowed us to observe the behavior of demand and its effect on supply chain management. 
Independent Journal of Management \& Production (IJM\&P) ISSN: 2236-269X DOI: 10.14807/ijmp.v3i1.22

v. 3, n. 1, January - June 2012

This comparative analysis of the behavior of demand and supply chain over the past four years, with the result that the model was allowed to observe the times the storage costs were above and below the model showed.

This analysis allowed us to observe the possible periods which increased the cost of storage, with an output higher than necessary and consequently a volume storage of raw material and finished product high.

Also allowed to observe the periods in which the volumes of stocks of finished products and raw materials were below the necessary and which consequently generated some kind of cost for loss of market.

According to board the mathematical model can support decision making as to what and how much to produce and when to start and end the production, they may add to the model the four product lines and observing the proportion to be produced for each product line months the month.

The model will also examine the quantities of raw materials purchased in the course of a year, observing the times of high prices, production and consumption of the finished products. This will support purchasing decisions and delivery. Allowing suppliers to organize and participate on the volumes to be delivered and their respective dates.

Also according to the board model was easy to understand and applicability also allowed to observe more clearly the monthly performance as the cost of production and storage of the product spiral notebook.

Another factor that the company found interesting was the development of the mathematical model on the platform and Excel with the ability to use other solutions that complement Excel, for example: Risk Solver Platform and Crystal Ball.

\section{REFERENCES}

ALLEN S. J.; SCHUSTER, E. W. (2004) Controlling the risk for a agricultural harvest. Manufacturing \& Service Opertions Management, v. 6, n. 3, p 225-236.

BERTRAND, J. W. M.; FRANSOO, J. C. (2002) Modeling and Simulation: Operations management research methodologies using quantitative modeling. International Journal of Operations \& Production Management, v. 22, n. 02, p. 241-264.

GARCÍA-DASTUGUE, S. J. (2003) Dynamic time-based postponement:

Conceptual development and empirical test. Ph.D, Ohio: Ohio State University. 
Independent Journal of Management \& Production (IJM\&P) ISSN: 2236-269X DOI: 10.14807/ijmp.v3i1.22 v. 3, n. 1, January - June 2012

GOLDBERG, D. E. (2000) Genetic algorithms in search, Optimization and Machine Leaning. Addison Wesley Limited.

GRAVES, S. C.; WILLEMS, S. P. (2000) Optimizing strategic safety stock placement in supply chains. Manufacturing and Service Operations Management, v. 2, n. 1, p. 68-83.

GRONDIN, F. (1998) Improvements of the dynamic programming algorithm for tree bucking. Wood and Fiber Science, v. 30, n. 1, p. 91-104.

KO, M.; TIWARI, A.; MEHNEN, J. (2010) A review of soft computing applications in supply chain management. Applied Soft Computing. V. 10, p. 661-674.

LAWRENCE, J. A.; PASTERNACK, B. A. (2001) Applied management science: modeling, spreadsheet analysis, and communication for decision making. 2 ed. New Jersey: Wiley.

ROGERS, P.; RIBEIRO, K. C. S.; ROGERS, D. (2004) Avaliando o risco na gestão financeira de estoques. In: SIMPOSIO DE ADMINISTRAÇÃO DA PRODUÇÃ̃O, LOGÍSTICA E OPREAÇÕES INTERNACIONAIS, 7., São Paulo. Anais... São Paulo: FGV, 1 CD-ROM. 